\title{
Ilhas sintáticas e plausibilidade semântica - um estudo de rastreamento ocular de frases com lacunas preenchidas em português brasileiro
}

\author{
Marcus Maia* \\ Amanda Moura \\ Moíra de Souza
}

\begin{abstract}
RESUMO
Este trabalho apresenta um experimento de rastreamento ocular em que se investiga o efeito da lacuna preenchida (ELP) em construções subjacentes e não subjacentes e em contextos semânticos de plausibilidade e de implausibilidade. Os resultados sugerem que configurações de ilhas sintáticas são percebidas rapidamente pelo processador, impedindo tanto a postulação do ELP, quanto a avaliação semântica de plausibilidade na seleção-s do complemento pelo verbo. Nas condições não subjacentes, o ELP se instancia e a avaliação semântica ocorre apenas posteriormente às decisões de análise sintática, não evitando o ELP, conforme predito pelos modelos de processamento do tipo syntax-first.
\end{abstract}

Palavras-chave: Rastreamento Ocular. Construções QU. Efeito da Lacuna Preenchida. Ilhas sintáticas. Plausibilidade semântica.

\section{Introdução}

As línguas humanas permitem aos seus falantes estabelecerem relações de dependência à distância entre as palavras de uma frase. Por exemplo, em frases da língua portuguesa, como as ilustradas nos exemplos em (1), a distância linear entre o sintagma QU “que livro", no início da frase, e a posição sintática de objeto direto do verbo ler, onde o sintagma é interpretado, parece poder ser aumentada indefinidamente, sem prejuízo para a gramaticalidade da frase:

(1) a. Que livro João leu_?

b. Que livro Maria perguntou se João leu_?

1 Marcus Maia é professor titular de Linguística do Departamento de Linguística e do Programa de Pós-graduação em Linguística da UFRJ. Amanda Moura e Moíra de Souza são bolsistas PIBIC (CNPq) orientadas pelo primeiro autor. 
c. Que livro Carlos acha que Maria perguntou se João leu_?

d. Que livro Luís disse que Carlos acha que Maria perguntou se João leu_?

Pelo menos desde Chomsky (1977), a teoria gerativa analisa frases como essas, como tendo sido derivadas via movimento do sintagma QU de sua posição argumental de base, conforme exemplificado em (2), para cada frase de (1), respectivamente:

(2) a. João leu que livro?

b. Maria perguntou se João leu que livro?

c. Carlos acha que Maria perguntou se João leu que livro?

d. Luís disse que Carlos acha que Maria perguntou se João leu que livro?

Segundo análise tradicional na teoria gerativa, o sintagma QU teria sido deslocado de sua posição in situ, em (2), para posição não argumental na periferia esquerda do período. Nos exemplos (1) acima, o sintagma Que livro foi movido de sua posição argumental de complemento do verbo ler, onde recebe caso e papel temático, podendo ser interpretado através de cadeia sintática que liga a posição de extração à posição de pouso.

Há, no entanto, diferentes contextos sintáticos que impedem a extração do sintagma QU, independentemente da distância linear entre os sítios de extração e de pouso. O trabalho clássico de Ross (1967) elenca uma série de configurações estruturais que bloqueiam o movimento de elementos QU. Por exemplo, frases como em (3) não parecem bem formadas em português brasileiro (PB):

(3) a. *Que livro João encontrou o professor que escreveu_?

b. * Por que o João perguntou que o professor escreveu um livro__?

c. *Que livro encontrar_é difícil?

d. *O que o João comprou um livro e__?

Em (3a), a extração do constituinte QU de dentro de uma oração relativa é agramatical; em (3b), a extração de dentro de uma oração factiva também é agramatical, assim como a extração de um sujeito sentencial em (3c) e de uma estrutura que é parte de um conjunto coordenado ${ }^{1}$ em (3d), igualmente, resultam em agramaticalidade. Esses e outros contextos sintáticos funcionam como ilhas, impondo restrições ao movimento QU, conforme descrito por Ross. Em busca de

1 Note-se que Ross (1967) indica que a extração de conjuntos coordenados só não resulta em agramaticalidade se o movimento for do tipo "across the board", em que o mesmo elemento é extraído de ambos os termos do conjunto coordenado, como, por exemplo, em "Que livro o professor escreveu_e perdeu_ na sexta, no parque?" Essas construções, portanto, não constituem ilhas sintáticas e a extração pode se dar, sem produzir agramaticalidade. 
adequação explicativa, para além do detalhamento descritivo aludido, Chomsky (1973) propõe a Condição de Subjacência, que captura propriedades comuns às construções de ilha descritas por Ross, indicando que o movimento QU não pode atravessar mais de um nó fronteira, sendo esses nós SN e S (DP e IP, em termos de hoje). Posteriormente, Rizzi (1982) propõe que os nós fronteiras relevantes para o italiano seriam, de fato, SN e S' (DP e CP), o que levará a uma parametrização do Princípio da Subjacência, sendo que o PB funciona como o italiano, nesse respeito.

Assim, em uma frase como (4a), o movimento do sintagma QU é licenciado pela gramática, pois atravessa apenas um nó fronteira, o DP. Em contraste, em uma frase como (4b) que contém um sintagma nominal complexo, formado por um DP e por uma oração relativa, o sintagma QU deveria atravessar dois nós fronteiras, a saber, o CP e o DP, violando o Princípio da Subjacência, e sendo, portanto, agramatical.

(4) a. Que livro [ ${ }_{\mathrm{DP}} \mathrm{o}$ professor escreveu_] [mas não ganhou dinheiro]?

b. *Que livro [ ${ }_{\mathrm{DP}}$ o professor [ CP $_{\mathrm{C}}$ que escreveu__ ] não ganhou dinheiro]?

No presente artigo, investigaremos se configurações de ilhas sintáticas são reais psicologicamente, através de um experimento de rastreamento ocular que compara a leitura de períodos com ilhas relativas a períodos coordenativos "across the board", que não constituem ilha sintática e não impõem, portanto, restrição à extração de sintagmas QU. Também é objeto de investigação, no estudo, o fator plausibilidade semântica, sendo que o contexto sintático e a plausibilidade semântica serão testados sistematicamente em um design fatorial que toma como diagnóstico o chamado efeito da lacuna preenchida (filled gap effect).

$\mathrm{O}$ artigo se organiza da seguinte maneira: na seção 2 , apresenta-se o efeito da lacuna preenchida (ELP) e revisa-se a literatura pertinente em inglês e em PB. $\mathrm{Na}$ seção 3, apresenta-se o experimento de rastreamento ocular que investiga o ELP em construções subjacentes e não subjacentes e em contextos semânticos de plausibilidade e de implausibilidade. Na seção 4, apresentam-se as conclusões do estudo.

\section{O Efeito da Lacuna Preenchida}

Uma das descobertas mais interessantes da especialidade da Psicolinguística conhecida como Processamento de Frases (Sentence Processing) é, sem dúvida, 
o chamado Princípio do Antecedente Ativo (Active Filler Principle). Trata-se, de fato, de um processo do tipo "top-down", no qual um elemento deslocado para a periferia esquerda da sentença ativamente busca um lugar em que possa ser interpretado, motivando a postulação de uma "lacuna como primeiro recurso". Há na literatura de Processamento, amplas evidências de que o processador sintático ou parser busca ativamente, ou "ansiosamente", no dizer de Wagers ; Phillips $(2006)^{2}$, completar uma dependência QU antes mesmo de encontrar o seu vestígio, na posição de onde o elemento QU foi extraído. Em trabalho clássico, Stowe (1986) encontrou tempos médios significativamente mais elevados na posição do objeto direto " $u s$ " em (5a) do que em (5b).

(5) a. My brother wanted to know who Ruth will bring / us / home to at Christmas.

b. My brother wanted to know if Ruth will bring / us / home to Mom at Christmas.

Ao contrário de if, que é gerado na base, who foi movido de sua posição de geração e o parser deve buscar a posição na estrutura oracional onde who pode ser interpretado, já que a posição em que se encontra $(S p e c, C P)$ seria não argumental, não atribuindo Caso e nem papel temático. Ao encontrar preenchida a posição de complemento verbal onde who poderia ter seus requisitos de Caso e papel temático satisfeitos, o parser entra em garden-path. $\mathrm{O}$ efeito surpresa, somado à reanálise estrutural imposta pelo garden-path seria responsável pelos tempos médios de leitura mais elevados encontrados no segmento do pronome us. O leitor precisaria recuperar-se do erro de análise que o levou, como primeiro recurso, a postular who como tendo sido extraído da posição de complemento de bring.

Encontrando aquela posição surpreendentemente preenchida, o processador busca, então, reestabelecer a cadeia correta do movimento QU, que teria seu pé na posição estrutural de complemento da preposição to, localizada mais adiante na oração. Como revisto em Maia (2014a), Frazier (1987), Frazier; Flores d'Arcais (1989) e Clifton; Frazier (1989), entre outros trabalhos, analisam o ELP como um caso de um princípio mais abrangente, incluído no âmbito das estratégias de economia da Teoria do Garden Path (TGP), o Active Filler Principle, traduzido em Maia; Finger (2005) como Princípio do Antecedente Ativo (PAA), que é formulado, nos termos de Clifton; Frazier (1989), da seguinte forma: "quando um antecedente de uma categoria XP tiver sido identificado em uma posição não

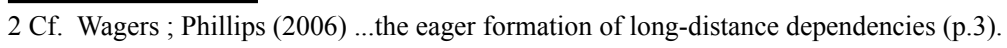


argumental, tal como COMP, ranqueie-se a possibilidade de atribuí-lo a uma lacuna correspondente na frase, acima da opção de identificar um sintagma lexical da categoria XP" ${ }^{3}$.

Revisitando o PAA, Wagers; Phillips (2009) avançam significativamente a discussão sobre a implementação on-line das condições gramaticais, demonstrando como o parser parece, de fato, ir além do simples cumprimento de um algoritmo de incrementacionalidade, mas ativamente procura satisfazer requisitos gramaticais. Wagers; Phillips testam, através de três experimentos de leitura automonitorada, a compreensão de conjuntos coordenados e lacunas parasíticas demonstrando diferenças importantes, que os levam a concluir que o processador não apenas respeita as condições gramaticais, mas procura aplicar a gramática. Suas conclusões são, de fato, diretamente relevantes para a especialidade mais recente, conhecida como Sintaxe Experimental ${ }^{4}$.

Sem dúvida, o debate central na especialidade Processamento de Frases e que, a nosso ver, também deve se colocar naturalmente na especialidade Sintaxe Experimental, por sua pertinência para o estabelecimento da arquitetura do conhecimento gramatical, diz respeito aos tipos de informação que são acessados no curso temporal da compreensão da linguagem. De um lado, teorias estritamente estruturais como a Teoria do Garden-Path (TGP) propõem que o processamento de frases é syntax-first, ou seja, as decisões de análise tomadas rapidamente durante a compreensão levam em conta, inicialmente, apenas informações sintáticas, tais como a categoria gramatical dos itens sendo incrementacional e economicamente estruturados. Do outro lado, encontram-se os modelos de satisfação de condições (e.g., MacDonald; Pearlmutter; Seidenberg,1994; McRae; Spivey-Knowlton; Tanenhaus, 1998), que postulam que todas as fontes de informação estariam disponíveis em paralelo, influenciando a análise em função dos pesos relativos que possam vir a ter no processo, sem priorização da informação sintática. Em tais modelos, a informação sintática competiria com informações semânticas,

3 When a filler of category XP has been identified in a non-argument position, such as COMP, rank the option of assigning its corresponding gap to the sentence over the option of identifying a lexical phrase of category XP.

4 Maia (2014b) analisa o processamento de construção gramatical em PB, tomando como diagnóstico o efeito da lacuna preenchida para discutir a interação interdisciplinar entre as áreas da Teoria Gramatical, da Sintaxe Experimental e do Processamento de Frases. Argumenta-se que os resultados de experimento de leitura automonitorada apresentado no artigo sugerem que a atribuição de papel temático alvo a um DP por um verbo ditransitivo é processada com menos prontidão do que a busca pelo recebimento de papel temático pelo DP alvo, indicando uma assimetria não prevista originalmente na formulação biunívoca do critério-theta. 
pragmáticas ou advindas do contexto discursivo, bem como relacionadas a fatores como a frequência e/ou a familiaridade dos sujeitos com a construção sendo processada. As duas classes de modelos tendem a convergir quanto à integração de todas essas informações na fase final da compreensão de frases, mas divergem quanto ao momento no tempo em que essas informações atuam, os modelos estruturais optando pela análise sintática exclusiva inicial, com eventuais revisões posteriores, motivadas por fatores semânticos, pragmáticos ou discursivos ou ainda pela frequência/familiaridade da construção. A tensão entre os dois modelos tem dominado a literatura de processamento de frases, motivando pesquisas que, do lado dos modelos estruturais, procuram demonstrar a realidade psicológica das estruturas sintáticas e a sua prioridade em relação aos demais fatores.

Em inglês, vários estudos experimentais testaram, por exemplo, se ilhas sintáticas são reais psicologicamente. Por exemplo, Stowe (1986) demonstra o efeito da lacuna preenchida em um primeiro experimento de leitura automonitorada para, em seguida, demonstrar, em um segundo teste usando a mesma técnica, que o efeito não ocorre em ilhas sintáticas. A não ocorrência do ELP em ilhas é também demonstrada para o Francês (Bourdages, 1992) e para o Japonês (Yoshida et al., 2004).

A testagem do ELP em ilha, em inglês, também foi feita em design considerando efeitos de plausibilidade da combinação entre o antecedente e o verbo. Traxler; Pickering (1996) demonstraram tanto efeitos resultantes de ilhas constituídas por orações relativas, quanto de plausibilidade, em estudos de rastreamento ocular. Os resultados dos experimentos de rastreamento ocular permitem aos autores identificar que o processador sintático apresenta indicadores de duração média das fixações mais lentos em sentenças gramaticais implausíveis, já na área do verbo, mas não parecem postular lacuna em contextos de ilha. No presente estudo, por outro lado, procuramos investigar se o contexto sintático subjacente impede a avaliação de plausibilidade.

Em português brasileiro, Maia (2014a) apresenta um estudo de rastreamento ocular e um de leitura automonitorada em que se estabelece a ocorrência do ELP em PB e se exploram efeitos de plausibilidade semântica. Os resultados detectam a presença do ELP (rastreamento ocular) e indicam que o parser atua de modo estritamente sintático em sua fase inicial (leitura automonitorada). Apresentamos na próxima seção o experimento de rastreamento ocular investigando o ELP, em PB, em contextos subjacentes e não subjacentes, em construções em que há plausibilidade ou implausibilidade na combinação entre o antecedente e o verbo. 


\section{O Experimento de Rastreamento Ocular}

O objetivo do estudo foi o de verificar, através da técnica de rastreamento ocular da leitura, se o parser exibe efeito da lacuna preenchida (ELP) em contextos sintáticos subjacentes e não subjacentes e em contextos semânticos de plausibilidade e de implausibilidade. A hipótese entretida é a de que o processador não exibiria nem efeito de lacuna preenchida e nem efeito de plausibilidade em contextos de subjacência. Prediz-se que os tempos médios de fixação e o número de visitas na área crítica sejam maiores nas condições não subjacentes do que nas condições subjacentes. Uma vez que não pode haver extração no contexto de ilha relativa, o parser acessaria esta informação sintática rapidamente e não postularia lacuna nesse contexto, evitando, portanto, efeito de lacuna preenchida. Da mesma forma, o processador não realizaria avaliação de plausibilidade semântica em contexto de ilha sintática, que já bloqueia previamente a postulação de lacuna em posição subjacente. Assim, haveria maior custo de processamento, indicativo do efeito da lacuna preenchida, nas condições não subjacentes do que nas condições subjacentes. Efeito de plausibilidade, se detectado on-line, seria instanciado apenas nas condições não subjacentes.

$\mathrm{O}$ experimento tem um design $2 \times 2$, em que a variável independente SUBJACÊNCIA, com dois níveis (Subjacente e Não subjacente) cruza fatorialmente com a variável independente PLAUSIBILIDADE, também com dois níveis (Plausível e Implausível), gerando quatro condições experimentais, a saber, (i) subjacente plausível (SP), (ii) subjacente implausível (SI), (iii) não subjacente plausível (NP) e (iv) não subjacente implausível (NI). As variáveis dependentes foram duas medidas on-line (duração total e número de fixações no segmento crítico) e uma medida off-line (índices de acerto e erro na questão interpretativa, ao final de cada frase). A medida off-line foi obtida através do registro dos índices de fixação ocular nos campos de respostas SIM ou NÃO, que se apresentavam abaixo da pergunta interpretativa, em tela que se seguia a cada frase. O Quadro (1) ilustra um conjunto de frases experimentais, com seus respectivos segmentos críticos sublinhados e suas questões interpretativas. 
QUADRO 1: Exemplos das condições experimentais com áreas críticas e questões interpretativas.

\section{Subjacente plausível (SP)}

Que livro o professor que escreveu a tese perdeu na sexta no parque?

O professor perdeu o livro? SIM NÃO

\section{Subjacente implausivel (SI)}

Que copo o professor que escreveu a tese perdeu na sexta no parque?

O professor perdeu o copo? SIM NÃO

\section{Não Subjacente plausível (NP)}

Que livro o professor escreveu a tese e perdeu na sexta no parque?

O professor perdeu o livro? SIM NÃO

\section{Não Subjacente implausível (NI)}

Que copo o professor escreveu a tese e perdeu na sexta no parque?

O professor perdeu o copo? SIM NÃO

\subsection{Método}

\section{Participantes}

32 alunos de cursos de graduação da UFRJ, com idade média de 21 anos, sendo 19 do sexo feminino; foram voluntários do experimento.

\section{$\underline{\text { Materiais }}$}

16 conjuntos de frases como o conjunto ilustrado no Quadro (1) foram preparados e distribuídos sistematicamente em quadrado latino em quatro versões do experimento, de modo a garantir que todos os sujeitos fossem expostos a todas as condições experimentais, mas não a frases com itens lexicais semelhantes. Em cada uma das quatro versões incluíram-se 48 frases distrativas, apresentadas em pseudorrandomização com as frases experimentais. As frases foram apresentadas em monitor de 23", acoplado ao rastreador ocular, em uma única linha, centralizada na tela, em fonte Courier New 16. Na tela das questões interpretativas, que sucedia a cada uma das frases, a pergunta a ser respondida era também exibida na mesma fonte e tamanho, com duas opções de resposta (SIM e NÃO), algumas linhas 
abaixo. O programa usado para apresentação, registro e análise dos materiais foi o Tobii Studio, versão 2.3.2.

\section{Procedimentos}

O experimento foi montado e aplicado no equipamento de rastreamento ocular Tobii TX300, acoplado a monitor de 23", na sala do Laboratório de Psicolinguística Experimental - LAPEX, na Faculdade de Letras da UFRJ. A tarefa solicitada a cada sujeito consistia na leitura automonitorada de frases, com resposta a questão interpretativa final, enquanto se monitorava o seu olhar através do rastreador. Inicialmente, sentava-se o sujeito a cerca de $65 \mathrm{~cm}$ da tela, procedendo-se à captura de seus olhos na tela do monitor e à calibração, fase em que o sujeito era instruído a fixar o olhar e a acompanhar o aparecimento e a movimentação de uma série de nove pequenos círculos na tela. A calibração era repetida, caso não se obtivessem parâmetros aceitáveis, conforme indicado pelo programa.

Obtendo-se boa calibração, passava-se à fase de prática em que o sujeito realizava a tarefa, sendo observado pelo experimentador. Após essa etapa, passavase ao experimento propriamente. Apertando um botão destacado em cor amarela, no teclado, o sujeito chamava à tela uma frase, devendo lê-la rapidamente, mas para compreensão. Havendo terminado a leitura, o sujeito apertava o botão amarelo novamente, chamando nova tela com uma pergunta interpretativa sobre a frase lida, que devia ser respondida rapidamente, olhando-se para o campo SIM ou para o campo NÃO, logo abaixo da pergunta. Respondida a pergunta, o sujeito pressionava novamente o botão amarelo, chamando à tela nova frase para leitura e interpretação, até que todas as 64 frases (16 experimentais e 48 distrativas) fossem apresentadas, momento em que a tela FIM aparecia para o sujeito, marcando o término do teste. De modo geral, cada sessão de teste tinha duração média de 20 a 25 minutos.

\subsection{Resultados}

Os tempos totais médios de fixação ocular na área crítica de cada condição experimental, mensurados em milésimos de segundo, estão apresentados no Gráfico 1, abaixo. Realizou-se uma ANOVA bifatorial por sujeitos, tomando-se como medidas repetidas os fatores SUBJACÊNCIA(S x NS) e PLAUSIBILIDADE $(\mathrm{P} \times \mathrm{I})$, em um design fatorial $2 \times 2$. O resultado da ANOVA indicou efeito principal altamente significativo do fator SUBJACÊNCIA $(\mathrm{F}(1,127)=33.3$ 
$\left.\mathrm{p}<0.000001^{* * *}\right)$ e efeito principal significativo do fator PLAUSIBILIDADE $(F(1,127)=4.06 p<0.046131)$, não se observando, no entanto, interação entre os dois fatores $(\mathrm{F}(1,127)=2.16 \mathrm{p}<0.144063 \mathrm{~ns}$. $)$. Foram também realizados testes- $\mathrm{t}$ pareados entre as condições relevantes. Há diferença significativa entre SP e NP $(t(127)=3.07 \mathrm{p}<0.0027)$ e entre SI e NI $(\mathrm{t}(127)=4.42 \mathrm{p}<0.0001)$, na direção esperada, em ambos os casos, ou seja, os segmentos críticos são processados mais rapidamente nas condições subjacentes do que nas condições não subjacentes, independentemente de sua plausibilidade, o que permite inferir que o efeito da lacuna preenchida não se instancia em ilha sintática.

A comparação de SP x SI não indica significância estatística no teste-t (t(127) $=0.18 \mathrm{p}<0.8564)$, permitido inferir que em contexto de ilha sintática também não se realiza avaliação de plausibilidade. Por outro lado, a comparação de NP x NI indica significância, na direção esperada $(\mathrm{t}(127)=2.10 \mathrm{p}<0.0373)$, ou seja, há maior custo de processamento para a lacuna preenchida em contexto não subjacente na condição implausível do que na condição plausível, o que permite inferir efeito on-line de avaliação de plausibilidade, nesta medida de tempo total de fixação ocular.

GRÁFICO 1: Tempos totais de fixação (ms) na área crítica por condição

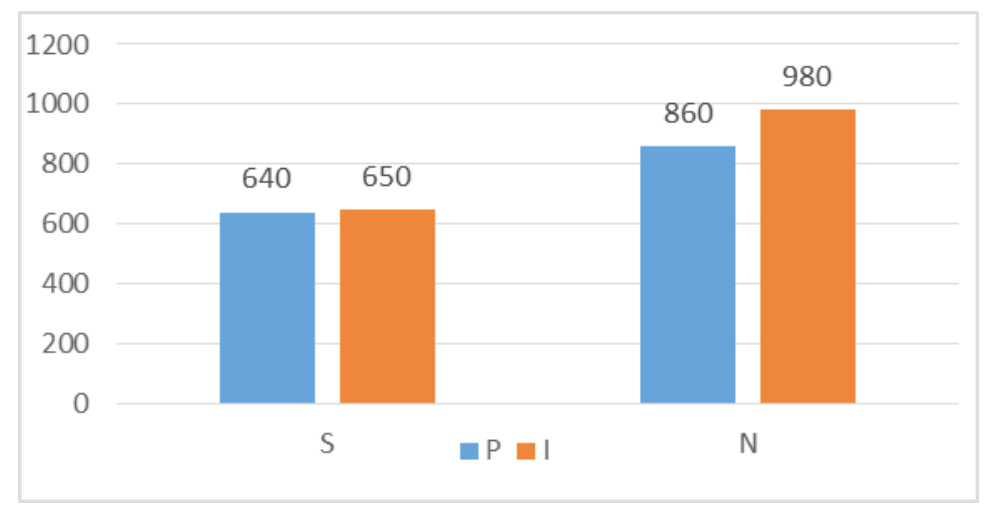

Além dos tempos totais de fixação nas áreas críticas, reportados acima, aferiu-se, também, o número total de fixações, progressivas e regressivas, nas mesmas áreas, conforme ilustrado no GRÁFICO 2. Uma ANOVA bifatorial por sujeitos indicou efeito principal altamente significativa do fator SUBJACÊNCIA 
$\left(\mathrm{F}(1,127)=18.7 \mathrm{p}<0.000030^{* * *}\right)$, mas não se observou nem efeito principal do fator PLAUSIBILIDADE $(\mathrm{F}(1,127)=2.55 \mathrm{p}<0.112619 \mathrm{~ns}$. $)$, nem interação entre os dois fatores $(\mathrm{F}(1,127)=0.969 \mathrm{p}<0.326850)$.

Testes-t pareados entre as condições relevantes indicaram que há diferença significativa entre SP e NP $(\mathrm{t}(127)=2.36 \mathrm{p}<0.0197)$ e entre SI e NI $(\mathrm{t}(127)=3.24$ $\mathrm{p}<0.0015)$, na direção esperada, em ambos os casos, ou seja, os segmentos críticos são processados com índices de fixação ocular significativamente menores nas condições subjacentes do que nas condições não subjacentes, independentemente de sua plausibilidade, o que permite inferir que o efeito da lacuna preenchida não se instancia em ilha sintática, confirmando o que já se observou na medida de tempos totais de fixação.

Também em linha com a medida de duração das fixações, a medida de número de fixações aferida na comparação entre SP x SI não indica significância estatística no teste-t $(\mathrm{t}(127)=0.35 \mathrm{p}<0.7267)$, confirmando que a plausibilidade não é avaliada em contexto de ilha sintática. Ao contrário, no entanto, do que se obteve na medida de tempo total de fixação, a medida do número de fixações não indica diferença de plausibilidade entre as condições não subjacentes plausível (NP) e implausível (NI), que obtêm índices estatisticamente não significativos quando comparadas no teste-t $(\mathrm{t}(127)=1.65 \mathrm{p}<0.1011 \mathrm{~ns}$. $)$.

GRÁFICO 2: Índices totais de fixação na área crítica por condição

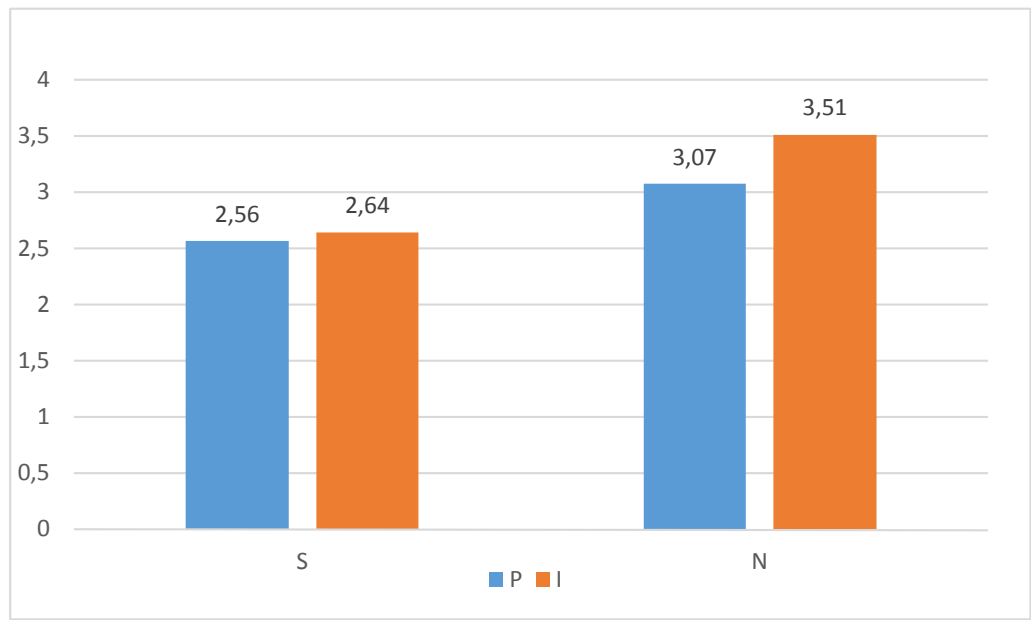


Observe-se, adicionalmente, que, já na área do verbo, encontra-se padrão de fixação indicativo de efeito de ilha e de plausibilidade, conforme indicado no gráfico 3:

GRÁFICO 3: Tempos totais de fixação (ms) na área do VERBO por condição

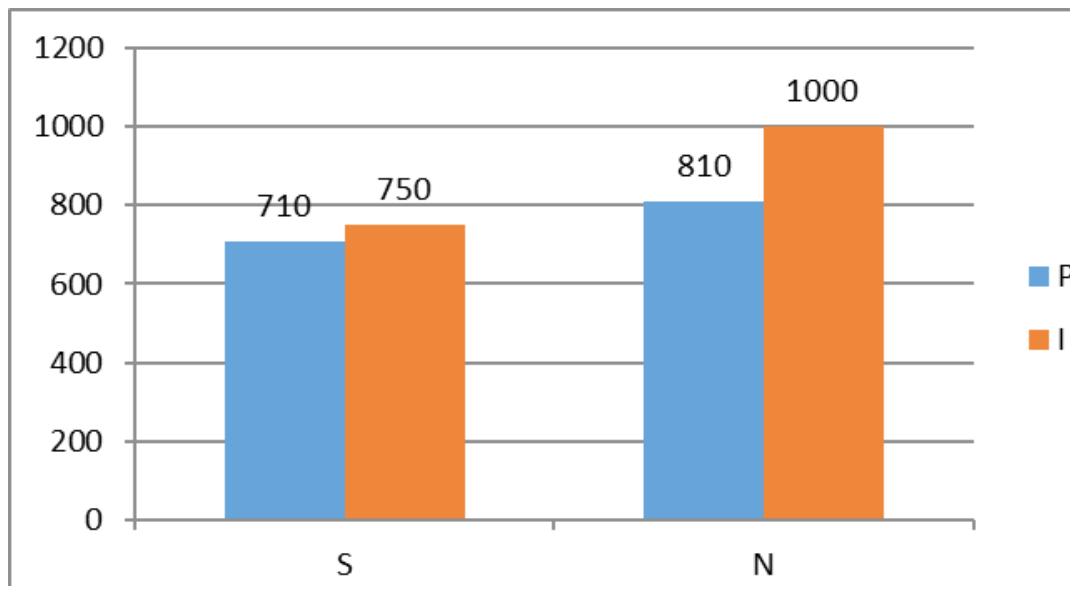

Há efeito principal altamente significativo de subjacência $(\mathrm{F}(1,127)=21.1$ $\left.\mathrm{p}<0.00001^{* * * *}\right)$ e efeito principal de plausibilidade $(\mathrm{F}(1,127)=6.18 \mathrm{p}<0.014239)$, embora, assim como observado na análise dos tempos de fixação do segmento crítico, não haja interação entre os dois fatores $(F(1,127)=1.87 \mathrm{p}<0.174048)$. Um teste-t pareado comparando as durações totais de fixação nas áreas do verbo e do segmento crítico que preenche a lacuna, nas condições plausíveis, indica diferença significativa na direção esperada $(\mathrm{t}(254)=2.11 \mathrm{p}<0.0355)$.

Observe-se que uma comparação entre os tempos médios de fixação da condição não subjacente plausível na área do verbo $(810 \mathrm{~ms})$ e na área da lacuna preenchida $(860 \mathrm{~ms})$ revela diferença significativa, na direção esperada $(\mathrm{t}(254)=$ $2.11 \mathrm{p}<0.0355)$, evidenciando, adicionalmente, o ELP. Por outro lado, a diferença entre os tempos médios de fixação da condição não subjacente implausível na área do verbo (1000ms) não difere significativamente dos tempos médios de fixação da condição não subjacente implausível na área da lacuna preenchida (980ms), indicando que o efeito de implausibilidade que já ocorre na área do verbo não aumenta significativamente na área da lacuna preenchida.

A medida de índices de fixação na área do verbo também indica efeito principal 
de subjacência $(\mathrm{F}(1,127)=5.63 \mathrm{p}<0.019)$ na direção esperada, embora não se registre nem efeito principal de plausibilidade $(\mathrm{F}(1,127)=0.587 \mathrm{p}<0.44)$ ou interação entre os fatores $(\mathrm{F}(1,127)=2.89 \mathrm{p}<0.09)$. O Gráfico 4 , abaixo, ilustra os índices de fixação por condição:

GRÁFICO 4: Índices de fixação na área do VERBO por condição

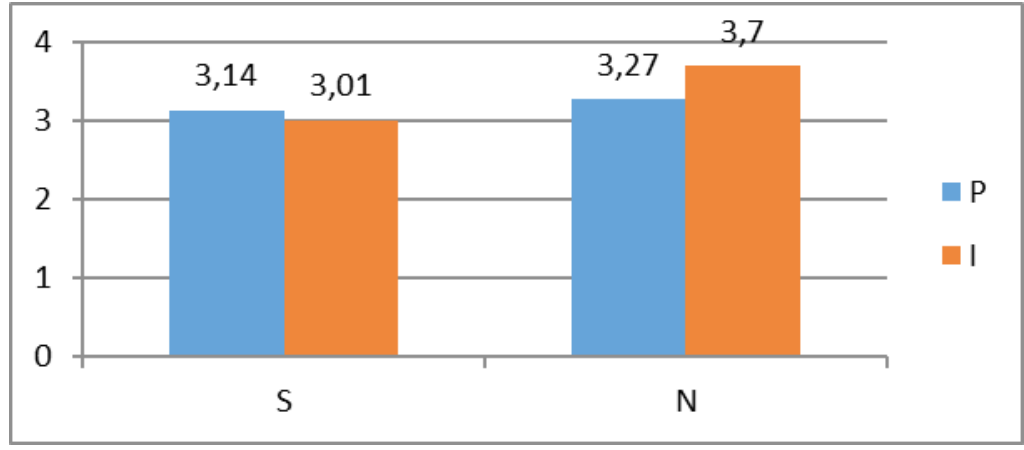

No que diz respeito às medidas off-line, obtidas através de índices de fixação do olhar nas respostas às perguntas interpretativas após cada frase, obtiveram-se os resultados representados no GRÁFICO 3.

GRÁFICO 3: Índice de acertos e erros por condição

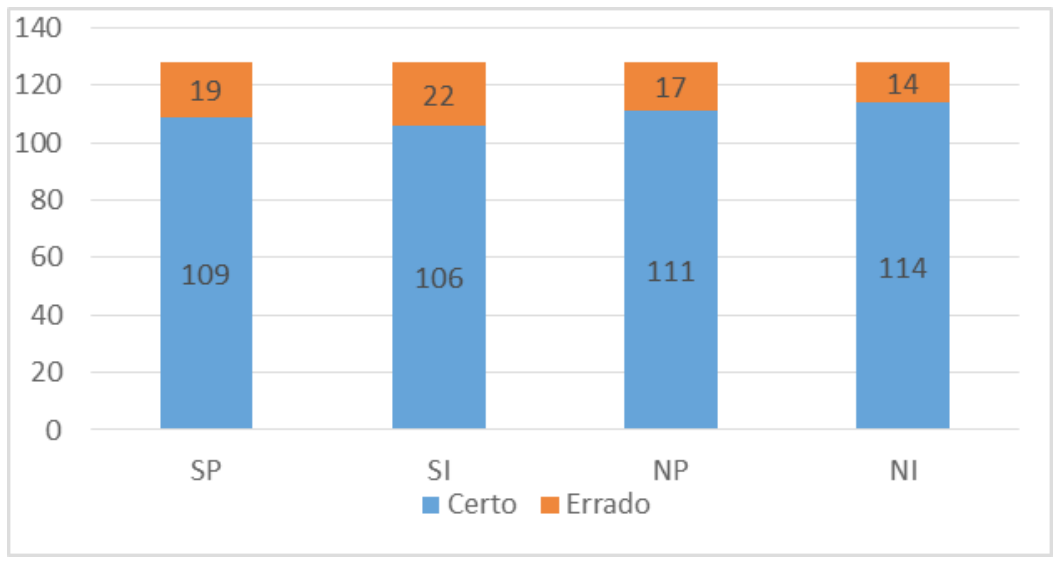


Convertidos os índices de acerto em termos percentuais, verifica-se que a condição SP obteve $85 \%$ de respostas corretas, a condição SI, $82 \%$ de respostas corretas, a condição NP, $87 \%$ de respostas corretas e a condição NI, $89 \%$ de respostas corretas, não se atestando nem efeito de subjacência e nem efeito de plausibilidade, conforme indicado pelo teste Chi quadrado $\left(\mathrm{X}^{2}(1,511)=0,1\right.$, $\mathrm{p}=0,74$ ns.). De modo geral, embora não permitindo identificar diferenças significativas entre as condições, nesta medida final ${ }^{5}$, o alto índice de acerto em todas as condições, em comparação aos índices de erro, atesta a confiabilidade do experimento.

\subsection{Discussão}

Como detalhamos acima, os resultados do experimento indicam diferença significativa, na área crítica da lacuna preenchida entre as condições subjacente e não subjacente, plausíveis ou não. Ou seja, o parser acessa rapidamente a informação sintática e, atento para a impossibilidade de extração em configuração de ilha, não postula lacuna após o verbo de oração relativa aposta a DP. Daí, as latências médias de fixação serem significativamente mais elevadas nas áreas críticas da condição NP do que da condição SP, conforme ilustrado pelos mapas de calor prototípicos abaixo. Observem-se os círculos nas Figuras 1 e 2.

FIGURA 1: Mapa de calor de frase subjacente plausível

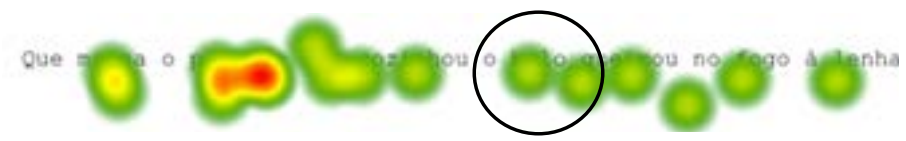

Que massa o padeiro que cozinhou o bolo queimou no fogo à lenha? (SP17)

5 Maia (2014a) encontrou efeito do tipo good enough nas medidas finais de experimento de rastreamento ocular, indicativo de que, mesmo tendo reanalisado o erro em que incorrera inicialmente, postulando como primeiro recurso lacuna em posição preenchida por SN, o parser persiste na análise incorreta. No presente experimento, tal efeito não parece ter se instanciado, uma vez que o índice de acerto é fundamentalmente o mesmo em todas as condições, sugerindo que esse tipo de análise superficial ou shallow seria instável e não determinístico. 
FIGURA 2: Mapa de calor de frase não subjacente plausível

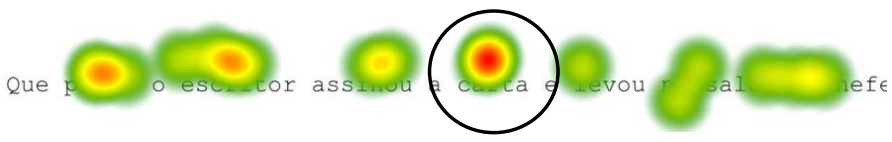

Que papel o escritor assinou a carta e levou na sala do chefe? (NP11)

A maior duração da fixação, expressa pelas cores amarela e vermelha, na área da lacuna preenchida na Figura 2 do que na área correspondente da Figura 1 ilustra o procedimento seletivo do parser: ilha sintática relativa não o engana e não há surpresa ou reanálise na posição do objeto direto pós-verbal que não preenche lacuna, simplesmente porque a posição subjacente não admite vestígio, então lacuna não há ali a ser preenchida. Daí não há ELP em SP. Por outro lado, em NP, coordenada across the board, há contexto legítimo para extração. O sintagma QU inicial procura, como primeiro recurso, posição no pé da cadeia onde possa receber caso, tornando-se visível para receber papel temático e ser interpretado. Esta posição poderia vir logo após o verbo. Entretanto, surpresa! Como exemplificado na Figura 2, o sintagma QU inicial Que papel, que poderia, legitimamente, ter saído da posição de objeto do verbo escrever, não pode, no entanto, ser construído nesta posição, que está preenchida pelo sintagma a carta. ELP claramente instanciado.

Note-se, crucialmente, que não há, no entanto, efeito de plausibilidade nas condições subjacentes (S). Será apenas nas condições não subjacentes $(\mathrm{N})$ que se observa avaliação semântica, sugerindo que a análise sintática precede a análise semântica, que fica condicionada ao licenciamento sintático, ao contrário do que obtiveram Traxler e Pickering (1996), que encontraram tanto efeitos resultantes de ilhas constituídas por orações relativas, quanto de plausibilidade, em estudos de rastreamento ocular com frases em inglês. Em nosso estudo, a avaliação de plausibilidade só ocorre em frases não subjacentes $(\mathrm{N})$, conforme ilustrado pelo contraste nas áreas críticas das frases exemplificadas nas Figuras 3 e 4.

FIGURA 3: Mapa de calor de frase não subjacente plausível
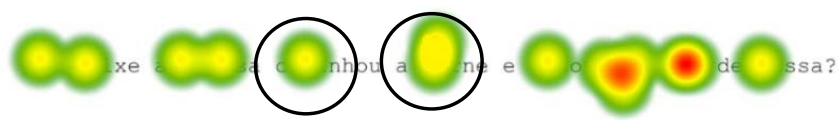

Que peixe a esposa cozinhou a carne e assou à noite depressa? (NP12) 
FIGURA 4: Mapa de calor de frase não subjacente implausível

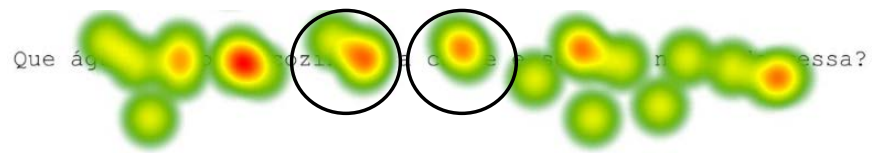

Que água a esposa cozinhou a carne e assou à noite depressa? (NI12)

O ELP continua a se instanciar na condição implausível da Figura 4, sendo sua latência ainda maior do que o ELP da Figura 3, como se vê contrastando as áreas críticas nos segundos círculos nos mapas de calor. Há, aí, efeito de plausibilidade. A avaliação semântica que aí ocorre não impede, no entanto, o efeito sintático do ELP, apenas o reforça. É como se o parser, ao processar uma frase como a ilustrada na Figura 4, ranqueasse a possibilidade de postular uma lacuna naquela posição, para usar os termos da formulação do Princípio da Aposição Ativa, acima da possibilidade de encontrar um DP preenchendo a lacuna, mesmo que esse DP fosse semanticamente implausível naquela posição. Novamente, temos aí evidência para a precedência da sintaxe sobre a semântica, como proposto por modelos syntax first. A avaliação de plausibilidade não impede o ELP e, podemos dizer, até o reforça. Note-se, nesses mesmos exemplos, que já na região do verbo o efeito de plausibilidade se instancia, como ilustrado pela comparação dos primeiros círculos das Figuras 3 e 4: as fixações são mais intensas no verbo cozinhar em (4) do que em (3). Em (4), o verbo cozinhar é implausível como selecionador de Que água como seu complemento, enquanto que, em (3), o sintagma QU Que peixe pode perfeitamente ser selecionado semanticamente pelo mesmo verbo cozinhar. Sem surpresa, como indicado pela fixação apenas verde no primeiro círculo da Figura (3). A detecção da implausibilidade semântica já no verbo não será capaz, no entanto, de evitar o ELP.

\section{Conclusões}

$\mathrm{O}$ experimento apresentado no presente artigo teve como objetivo entender as escolhas do processador sintático em tempo real, aferindo como ele toma decisões rapidamente em configurações subjacentes e não subjacentes e em contextos de plausibilidade e de implausibilidade. Os resultados expostos e discutidos acima indicam que o processador sintático não parece detectar o efeito 
da lacuna preenchida em contexto de subjacência. Os tempos médios de fixação e revisitações nas áreas críticas foram substancialmente maiores em contextos de condição não subjacente, tais como os conjuntos relativos across the board, onde não há ilhas sintáticas barrando o movimento de extração, do que em configurações subjacentes. Nestas, o parser imediatamente identifica a presença da ilha sintática e não postula lacuna, otimizando tanto os tempos médios de fixação, quanto os índices sacádicos, uma vez que a extração de elementos do interior de oração relativa apensa a DP, formando DP complexo, derivaria sentença agramatical.

Os resultados também indicam que a inspeção da legitimidade sintática, já na fase on-line do processamento da linguagem, parece preceder a inspeção sobre a plausibilidade semântica, que só se instancia nas construções não subjacentes, ao contrário de resultados reportados para o inglês por Traxler; Pickering (1996), que encontram efeitos de ilha e de plausibilidade, mas não aferem a precedência dos primeiros sobre os segundos. O presente trabalho fornece, portanto, dados relevantes tanto para o estudo sobre a formação de dependências sintáticas, quanto para o importante debate sobre a natureza das informações acessadas na fase on-line do processamento, tendo o potencial de contribuir para se avançar a compreensão sobre a arquitetura da capacidade humana da linguagem e de sua implementação on-line.

\begin{abstract}
This paper presents an eye-tracking experiment investigating the filled gap effect (FGE) in subjacent and non subjacent constructions in Brazilian Portuguese in a $2 \times 2$ design in which the plausibility of the verb complement s-selection is also tested. The results suggest that syntactic island configurations are quickly perceived by the parser, preventing both the postulation of the FGE, and the plausibility evaluation of the verb complement s-selection. In non subjacent conditions, the FGE is instantiated and the semantic evaluation occurs only subsequent to parsing decisions, not avoiding the FGE, as predited by syntax-first processing models.
\end{abstract}

Keywords: Eye Tracking. WH-constructions. Filled Gap Effect. Syntactic island. Semantic plausibility. 
Referências

BOURDAGES, Johanne S. Parsing complex NPs in French. In GOODLICK, H.; S.ROCHEMOND, M. (eds.), Island constraints: Theory, acquisition and processing. Dordrecht: Kluwer. 61-87. 1992

CHOMSKY, Noam. Conditions on Transformations. In: ANDERSON, S.R. e P. KIPARSKY (eds.). A Festschrift for Morris Halle. Holt, Reinehart and Winston, Inc., New York. 1973.

CHOMSKY, Noam. On Wh-Movement. In CULICOVER, P., WASOW, T., and AKMAJIAN, A., (Eds). Formal Syntax. New York: Academic Press. pp. 71-132. 1977.

CLIFTON, C. ; FRAZIER, L. Comprehending sentences with long-distance dependencies. In TANENHAUS, M.K. ; CARLSON, G. (Eds.). Linguistic structure in language Processing. Dordrecht: Kluwer Academic Press. 1989.

FRAZIER, L. Syntactic processing: Evidence from Dutch. Natural Language and Linguistic Theory 5: 519-560. 1987.

FRAZIER, L; FLORES D'Arcais, G.B. Filler-driven parsing: a study of gap filling in Dutch. Journal of Memory of Language 28: 331-44. 1989.

McDONALD, M.C., PEARLMUTTER, N.J.; SEIDENBERG, M.S. The lexical nature of syntactic ambiguity resolution. Psychological Review. 101, 676-703. 1994.

MAIA, Marcus. Efeito da lacuna preenchida e plausibilidade semântica no processamento de frases em português brasileiro. Cadernos de Letras da UFF, v. 49, p. 23-46. 2014a.

MAIA, Marcus; FINGER, Ingrid (Org.). Processamento da Linguagem. 1. ed. Pelotas, RS: EDUCAT, 2005. 535p. 2005.

MAIA, Marcus. Teoria gramatical, sintaxe experimental e processamento de frases: explorando efeitos do antecedente e da lacuna ativos. Revista da ABRALIN, v. 13, p. 95-120. 2014b.

McRAE, K.; SPIVEY-KNOWLTON, M. J.; TANENHAUS, M. K.. Modeling the influence of thematic fit (and other constraints) in on-line sentence comprehension. Journal of Memory and Language, 38, 283-312. 1998.

RIZZI, L. Issues in Italian Syntax, Foris, Dordrecht. 1982. 
ROSS, J.R. Constraints on Variables in Syntax, Dissertação de PhD, MIT. 1967

STOWE, Laurie. Parsing wh-constructions: evidence for on-line gap location. Language and Cognitive Processes 1. 227-46.3. 1986.

TRAXLER MJ ; PICKERING MJ. Plausibility and the processing of unbounded dependencies: An eyetracking study. Journal of Memory and Language, 35: 454-475. 1996.

WAGERS, M., and PHILLIPS, C. (Re)active filling. Talk presented at the 19th Annual CUNY Conference on Human Sentence Processing, New York. 2006.

WAGERS, M., and PHILLIPS, C. Multiple dependencies and the role of the grammar in real-time comprehension. J. Linguistics 45 (2009), 395-433. 2009.

YOSHIDA, M., AOSHIMA, S., and PHILLIPS, C. Relative clause prediction in Japanese. Talk presented at the 17th Annual CUNY Conference on Human Sentence Processing, College Park,Md.

Submetido: 27/02/2016

Aceite: 08/07/2016 